Gestión y Estrategia

Gestão e Estratégia

Management and Strategy

\title{
La RESPONSABILIDAD INTERNACIONAL DEL Estado Colombiano ANTE LA CoRTE INTERAMERICANA DE Derechos Humanos POR LA INOPERANCIA DE LA JUSTICIA INTERNA'
}

RESPONSABILIDADE INTERNACIONAL DO ESTADO COLOMBIANO FRENTE A CoRTE INTERAMERICANA dE DIREITOS Humanos POR A INOPERÂNCIA DA JUSTIÇA INTERNA²

International Responsibility of the Colombian State Facing the Inter-American Court on Human Rights for THE INEFFECTIVENESS OF INTERNAL JUSTICE ${ }^{3}$

Mayra Mestizo Sosa ${ }^{4}$

Escuela Superior de Guerra

\section{CIENCIA Y PODER AÉREO}

ISSN 1909-7050 / E- ISSN 2389-2468 / Volumen 10 / Enero-Diciembre de 2015/ Colombia/ Pp. 1-260

Recibido: 16/09/2015

Aprobado evaluador interno: 05/10/2015

Aprobado evaluador externo: 02/11/2015

Doi: http://dx.doi.org/10.18667/cienciaypoderaereo.157 
CIENCIA Y PODER AÉREO | Revista Científica de la Escuela de Postgrados de la Fuerza Aérea Colombiana | Vol. 10 | Enero - Diciembre de 2015

\section{Para citar este artículo:}

Mestizo, M. (2015). La responsabilidad internacional del Estado colombiano ante la Corte Interamericana de Derechos Humanos por la inoperancia de la justicia interna. Ciencia y Poder Aéreo, 10 (1), 91-108. Doi: http://dx.doi. org/10.18667/cienciaypoderaereo.157

\footnotetext{
' Artículo de reflexión derivado de la investigación presentada como trabajo de grado para optar al título de Magíster en Derechos Humanos y Derecho Internacional de los Conflictos Armados de la Escuela Superior de Guerra, siendo producto del proyecto de Investigación "Derecho Operacional como instrumento eficaz para la protección de la población civil y la seguridad jurídica institucional como individual en Colombia" vinculado al grupo de investigación "DDHH, DICA y Justicia"; inscrito en Colciencias, avalado por la Escuela Superior de Guerra. Bogotá, Colombia.

${ }^{2}$ Artigo de reflexão derivado da pesquisa apresentada como uma opção para obter o título de Mestre em Direitos Humanos e Direito Internacional dos conflitos armados da Escola Superior de Guerra, sendo o produto do projeto de pesquisa "Direito Operacional como um instrumento eficaz para a protecção de civis e segurança jurídica institucional como um indivídual na Colômbia "ligado ao grupo de pesquisa DDHH, DICA e Justiça "; registrado em Colciencias, aprovado pela Escola Superior de Guerra. Bogotá Colômbia.
}

${ }^{3}$ Reflection article derived from research paper presented as an option to obtain the title of Master on Human Rights and International Law of Armed Conflict at the Colombian War College, being the product of the research project "Operational Law as an effective instrument for the protection civilians and institutional security law as an individual in Colombia "linked to the research group" DDHH, DICA and Justice "; registered in Colciencias, endorsed at the Colombian War College. Bogotá, Colombia.

${ }^{4}$ Ingeniera Industrial egresada de la Universidad Autónoma de Colombia. Especialista en Producción Industrial, Control Fiscal y Ambiental, Estándares Internacionales de Calidad, Medio Ambiente, Seguridad Industrial, Salud Ocupacional y Aseguramiento Metrológico Industrial, Instructor en Empresas del Estado de primer nivel. Ejecutor del convenio interinstitucional FFMM-SENA, Consultor y Asesor en Sistemas Integrados de Gestión. Colombia. Correo electrónico: mmayramestizo@yahoo.com
Resumen: en la actualidad la responsabilidad internacional del Estado Colombiano ante la Corte Interamericana de Derechos Humanos, evidencia un aumento de las violaciones a los estándares que contempla el Derecho Internacional de los Derechos Humanos, que exponen una situación compleja en la justicia interna, en una ausente dinámica procesal que perfeccione la instrucción del proceso y esclarezca las circunstancias y responsabilidades a que haya lugar. Se identifica un patrón de solución, proporcional a cada fase de la Administración de Justicia, correspondiente en su orden a la indagación e investigación, proporcionando un método de orientación, basado en el equilibrio de modelos matriciales, efectivos a la hora de formular una justicia clara e evidente, lo cual indica tener la capacidad de identificar lo simple de lo complejo, ante la inoperancia de la justicia interna. La metodología utilizada fue analítica, de tipo documental y explicativa, teniendo como soporte principal la Convención Americana de Derechos Humanos. En conclusión el Estado Colombiano debe generar mecanismos de seguimiento, monitoreo y control con criterios de transparencia, objetividad e independencia en los macros y micros procesos de la Administración de Justicia. Además de la implementación adecuada y eficiente de una Estrategia Jurídica Ordenada que proporcione una verdadera evolución jurídica.

Palabras clave: administración de justicia; Corte Interamericana de Derechos Humanos; derechos humanos; responsabilidad del Estado; teoría del equilibrio.

Resumo: atualmente, a responsabilidade internacional do Estado colombiano frente à Corte Interamericana de Direitos Humanos, mostra um aumento nas violações das normas consagradas no Direito Internacional dos Direitos Humanos que expõem uma situação complexa nos tribunais nacionais, numa dinâmica processual ausente que melhore a instrução do processo e esclareça as circunstâncias e responsabilidades que possam ser necessárias. Identifica-se um padrão de solução proporcional a cada fase da Administração da Justiça, correspondente à pesquisa e investigação, fornecendo um método de orientação com base no equilíbrio de modelos matriciais efetivos na formulação de uma justiça clara e evidente, o que é sinónimo de ter a capacidade de identificar o simples do complexo face à ineficiência da justiça interna. A metodologia utilizada foi do tipo analítica, documental e explicativa, tendo como principal suporte a Convenção Americana sobre Direitos Humanos. Em conclusão, o Estado colombiano deve criar mecanismos de rastreamento, monitoramento e controle baseado em transparência, objetividade e independência nos macro e micro processos de administração da justiça. Além da adequada e eficiente implementação da estratégia jurídica ordenada para fornecer uma verdadeira evolução jurídica.

Palavras-chave: administração justiça; a teoria do equilíbrio; Corte Interamericana de Direitos Humanos; direitos humanos; responsabilidade do Estado.

Abstract: Currently the international responsibility of the Colombian State facing the Inter-American Court of human rights, shows an increase in violations of standards contemplated by the international law of human rights, which expose a complex situation at the internal justice in a missing procedural dynamic that improves the process instruction and clarifies the circumstances and responsibilities required. A pattern of solution proportional to each stage of the administration of Justice is identified, corresponding to inquiry and research and providing an orientation method based on the balance of matrix models, efficient when formulating a clear and evident justice, which means having the ability to identify the simple from the complex facing the ineffectiveness of the internal justice. The methodology used was analytical, documentary and explanatory, having as main support the American Convention on human rights. In conclusion, the Colombian State must generate monitoring and control mechanisms with transparency, objectivity and independence criteria in the macro and micro processes of the administration of Justice. In addition, proper and efficient implementation of a ranked legal strategy, that provides a true legal evolution.

Key Words: Administration Justice; Equilibrium Theory; Human Rights; Inter-American Court of Human Rights; State Responsibility. 


\section{Introducción}

El Derecho Internacional de los Derechos Humanos en su doctrina, ha sido reiterativo en la responsabilidad internacional de los Estados. La pregunta que se aborda es: ¿Cuál es el patrón que incide, en el aumento de los casos emitidos en sentencia por la Corte Interamericana de los Derechos Humanos, como resultado de las violaciones a los estándares que contempla el derecho internacional de los derechos humanos?

En este sentido, resulta de vital importancia, realizar un análisis estructural respecto de la responsabilidad internacional del Estado colombiano ante el sistema interamericano, considerando, el ámbito de aplicabilidad de los diferentes instrumentos normativos de carácter internacional, específicamente de la Convención Americana sobre Derechos Humanos, que ha sido, base fundamental en la interpretación y aplicabilidad normativa, en materia de derechos humanos para el sistema regional. La cooperación internacional aporta un planteamiento considerable en el desarrollo y evolución de los derechos humanos como producto jurídico de la modernidad, en la relación protección y garantía; que sugieren el fortalecimiento de las dinámicas procesales, una aceleración de los procesos de implementación a nivel nacional y un afianzamiento en la observancia, interpretación y aplicación de los tratados.

En este orden de ideas, no cabe duda, que sin la implementación de mecanismos de seguimiento, monitoreo y control interinstitucional (Altas Cortes, Fiscalía y Ministerio Público) de carácter alternativo, rápido, confiable y económico. Se alejará, en la medida posible, la identificación objetiva de las fortalezas y debilidades que rodean la óptica de la legalidad, en el orden y la justicia.

En particular, se propone adoptar las medidas necesarias para prevenir y corregir los elementos que impiden esclarecer la responsabilidad del Estado. Para ello, se formula un sistema de equilibrio, que tendrá como base Annals of Mathematics Non Cooperative Games de John Nash, donde se generan patrones de solución basados en la cooperación, para las fases I y || correspondientes a la indagación e investigación en la administración de justicia; ya que una verdadera seguridad para los nacionales de este país, se encuentra configurada en el marco de un Estado social de derecho, que fortalecerá, la protección de los derechos y libertades, en una eficaz e eficiente articulación con los procesos de justicia, concibiendo la adaptación propositiva de una Estrategia jurídica ordenada que aporte una solución en la óptica de la legalidad.

\section{Método}

El presente artículo, ofrece el desarrollo de la siguiente metodología: en primer lugar, se realiza un análisis sintético de los elementos normativos del Derecho Internacional de los Derechos Humanos, en donde se identifican las competencias y funciones de la Comisión y la Corte Interamericana de Derechos Humanos, se examina la jurisprudencia referente a los deberes de los Estados y derechos protegidos contenidos en la Convención Americana sobre Derechos Humanos. En segundo lugar, se expone la responsabilidad internacional del Estado ante el sistema interamericano, identificando los elementos que en conjunción, configuran la identificación y posterior calificación del hecho internacionalmente ilícito, que acarrea su responsabilidad internacional y expone en ocasiones la generación de nuevas obligaciones jurídicas bilaterales o con toda la comunidad internacional. En tercer lugar, en dicha sección se exponen las obligaciones ante el sistema interamericano, de acuerdo a lo consagrado en la Convención Interamericana de Derechos Humanos e inclusive una adaptación del deber de garantía, en el derecho interno. Finalmente, en la sección cuatro, se identifica el patrón de solución de la administración de justicia, que sugiere la exigibilidad de mecanismos transparentes, independientes y de cooperación para llevar a cabo las investigaciones necesarias.

\section{Elementos normativos del derecho internacional de derechos humanos}

Para empezar es importante hacer claridad respecto del marco terminológico de una de las especialidades del derecho internacional. El Derecho Internacional de los Derechos Humanos, es una rama especializada en torno a la protección internacional de los derechos humanos, tanto los de carácter civil y político, como los de índole económica, social y cultural.

Asimismo, se deben identificar los mecanismos de protección de los derechos humanos del orden regional e identificar los ámbitos normativos que formulen las obligaciones para los Estados partes; para las Américas, sea dispuesto del Sistema Interamericano de Protección de los Derechos Humanos. Los principales instrumentos que lo rigen son:

- * *a Declaración Americana de Derechos y Deberes del Hombre, Bogotá 1948.

- * *La Convención Americana de Derechos Humanos, San José de Costa Rica 1969.

- * La Convención Interamericana para Prevenir y Sancionar la Tortura, Cartagena, 1985. 
CIENCIA Y PODER AÉREO | Revista Científica de la Escuela de Postgrados de la Fuerza Aérea Colombiana | Vol. 10 | Enero - Diciembre de 2015

- *Protocolo a la Convención Americana sobre derechos económicos, sociales y culturales.

- *Protocolo a la Convención Americana sobre la Abolición de la pena de muerte, Asunción 1990.

- $\quad{ }^{*}$ Convención interamericana sobre Desaparición forzada de personas, 1994.

- $\quad{ }^{*}$ Convención para prevenir, sancionar y erradicar la violencia contra la Mujer, Belem do Para, 1994.

- $\quad{ }^{*}$ Convención Americana para la eliminación de todas las formas de discriminación contra las personas con discapacidad, Guatemala ,1999.

Los Pactos internacionales de derechos humanos y las múltiples convenciones sobre el tema han sido adoptadas dentro del marco normativo de las Naciones Unidas y por consiguiente por los sistemas regionales (Camargo, 2012, p. 39). El Sistema Interamericano de Protección de los Derechos Humanos se encuentra conformado por dos mecanismos esenciales: la Comisión y la Corte Interamericanas de Derechos Humanos.

La Comisión Interamericana de Derechos Humanos (en adelante "Comisión IDH"), tiene su sede en Washington, D.C., fue creada en la quinta reunión de consulta de los Ministros de Relaciones Exteriores del continente americano en Santiago de Chile en 1959, la Comisión IDH tiene una doble competencia como órgano de tutela del "Pacto de San José" y al propio tiempo, es una "entidad autónoma y órgano consultivo en materia de derechos humanos" de la OEA establecido para ejercer la observancia y defensa permanente de los derechos humanos (Nikken, 1989, p.18).

Uno de los principales instrumentos del Sistema Interamericano de Protección de los Derechos Humanos es la Convención Americana sobre Derechos Humanos (en adelante Convención o "CADH") que fue suscrita en San José de Costa Rica el 22 de noviembre de 1969, en la Conferencia especializada interamericana sobre derechos humanos, y entró en vigor el 18 de julio de 1975, conforme al artículo 74.2.

Ahora bien, la Corte Interamericana de Derechos Humanos (en adelante Corte IDH), tiene su sede en San José de Costa Rica, es una institución judicial autónoma cuyo objetivo es la aplicación e interpretación de la Convención y de otros tratados concernientes a la protección de los derechos humanos en los Estados americanos (....) como lo dispone el artículo 64, ejerce sus competencias y funciones de conformidad con la Convención y su Estatuto; la función jurisdiccional de la Corte IDH es opcional o facultativa como lo preceptúa la Convención:
Todo Estado parte puede, en el momento del depósito de su instrumento de ratificación o adhesión de esta Convención, o en cualquier momento posterior, declarar que reconoce como obligatoria de pleno derecho y sin convención especial, la competencia de la Corte sobre todos los casos relativos a la interpretación o aplicación de esta convención (OEA,CADH,1969, art. 62.1).

La Corte IDH también tiene competencia sobre los casos examinados previamente por la Comisión IDH (O'Donnell, 2012). El artículo 62.3, comprende que esta competencia se limita a cualquier caso «(...) relativo a la interpretación y aplicación de las disposiciones de esta Convención que le sea sometido, siempre que los Estados partes en el caso hayan reconocido o reconozcan dicha competencia». (s.p.)

Cuando la Corte IDH decida que hubo violación de un derecho o libertad protegidos en esta Convención, la Corte IDH dispondrá que se garantice al lesionado en el goce de su derecho o libertad conculcados. Dispondrá asimismo, si ello fuera procedente, que se reparen las consecuencias de la medida o situación que ha configurado la vulneración de esos derechos y el pago de una justa indemnización a la parte lesionada. En casos de extrema gravedad y urgencia, puede adoptar las medidas provisionales que considere pertinentes como lo reconoce el artículo 63 de la Convención.

En cuanto a sus competencias procedimentales, el fallo de la Corte IDH será definitivo e inapelable como lo establece el procedimiento en el artículo 66,67 y 68 de la Convención. Los Estados partes se comprometen a cumplir la decisión de la Corte IDH, en todo caso en que sean partes. La parte del fallo que disponga indemnización compensatoria se podrá ejecutar en el respectivo país por el procedimiento interno vigente para la ejecución de sentencias contra el Estado.

El artículo 75 de la Convención, reafirma que solo puede ser objeto de reservas conforme a las disposiciones de la Convención de Viena sobre Derechos de los Tratados. En estos términos el Estado colombiano, hace reconocimiento de la competencia:

El 21 de junio de 1985, en dónde, presentó un instrumento de aceptación por el cual reconoce la competencia de la Comisión IDH por tiempo indefinido bajo condición de estricta reciprocidad y para hechos posteriores a esta aceptación, sobre casos relativos a la interpretación o aplicación de la Convención, reservándose el derecho de hacer cesar la competencia en el momento que lo considere oportuno. El mismo instrumento reconoce la competencia 
de la Corte IDH por tiempo indefinido, bajo condición de reciprocidad y para hechos posteriores a esta aceptación, sobre casos relativos a la interpretación o aplicación de la Convención, reservándose el derecho de hacer cesar la competencia en el momento que lo considere oportuno (OEA, CADH, 1974, Tratados No 36).

Es de aclarar que el derecho internacional en general, lo es especialmente en materia de derechos humanos, en la cual, no solo se incluyen ámbitos normativos de derechos y garantías, sino a su vez condensa para los Estados partes las respectivas obligaciones acerca de la manera como se aplican todas las facultades del poder, como lo contiene el Pacto Internacional de Derechos Civiles y Políticos de 1966 (en adelante PIDCP).

Cada Estado Parte se compromete a adoptar, con arreglo a sus procedimientos constitucionales y a las disposiciones del presente Pacto, las medidas oportunas para dictar las disposiciones legislativas o de otro carácter que fueren necesarias para hacer efectivos los derechos reconocidos en el presente Pacto y que no estuviesen ya garantizados por disposiciones legislativas o de otro carácter (PIDP, 1966, art. 2.2).

El PIDCP fue ratificado por Colombia el 29 de octubre de 1969, previa aprobación por el Congreso de la República mediante Ley № 74 de 1968, y entró en vigor de acuerdo con las disposiciones del instrumento el 23 de marzo de 1976. Ante las Naciones Unidas en el examen de los informes presentados por los Estados partes en virtud del artículo 40 del Pacto; según el sexto informe periódico de los Estados partes Colombia 10 de diciembre de 2008.

En esta aplicación los Estados partes se comprometen a adoptar las medidas necesarias y suficientes de justicia, tanto de orden interno, como mediante la cooperación entre los Estados, a fin de lograr progresivamente la efectividad de estos derechos, Tratado Internacional, Sentencia ( 251/1997).

En la actualidad, la jurisprudencia internacional ha sido reiterativa en que se aplica todos los hechos ilícitos de un Estado: en primer lugar, cuando, su proceder puede consistir en una o varias acciones $u$ omisiones o en una combinación de ambas cosas (Rodríguez, 2006, p. 51) y en segundo lugar, cuando ese proceder constituye una violación de una obligación internacional del Estado, tanto de carácter convencional (tratados) como consuetudinario "La costumbre internacional como prueba de una práctica generalmente aceptada como derecho"; lo expresa el artículo 38.b., del Estatuto de la Corte Internacional de Justicia; siguiendo a (Camargo. 2013, p. 15) estas normas constitu- yen el sistema contemporáneo normativo obligatorio del derecho internacional. Por otro lado, cuando un Estado suscribe un tratado, su consentimiento expreso hace posible la existencia de determinadas reglas jurídicas convencionales internacionales, estás medidas están insertas en la Convención de Viena sobre el Derecho de los Tratados que fue suscrita en Viena (Austria) el 23 de mayo de 1969. Así, la Comisión de Derecho Internacional, de la Asamblea General de la ONU decidió que los tratados celebrados entre Organismos Internacionales, o entre Organismos Internacionales y Estados, serían objeto de otra Convención, la cual fue adoptada el 21 de marzo de 1986. Las normas de derecho Internacional reflejadas en las Convenciones de Viena de 1969 y de 1986 establecen un sistema flexible y adaptable a diversos tipos de tratados. Según el Congreso de la República, (1985) el Gobierno colombiano ratifica la Convención de Viena el 10 de abril de 1985.

Según Villacís, (2006) consta de 85 artículos; y, entró en vigencia el 27 de enero de $1980^{\prime}$ en los artículos 26 al 38, se observa la siguiente estructura: 1) Observancia de los tratados; 2) Aplicación; 3) Interpretación; 4) Los tratados y los terceros Estados; en donde, análogamente se definen elementos propios de gestación de los principios generales del derecho en materia de derechos humanos.

Al respecto, el artículo 31.1, contiene la Regla General de Interpretación "Un tratado deberá interpretarse de Buena fe conforme al sentido corriente que haya de atribuirse a los términos del tratado en el contexto de estos y teniendo en cuenta su objeto y fin", preceptúa el principio de Buena fe, que constituye uno de los pilares de todo régimen jurídico "al poner límites a la discrecionalidad de los Estados en el ejercicio de sus competencias soberanas" (Vasco, 2003, p. 3).

En este sentido, se encuentra inmerso, también, en el artículo 26, "Pacta Sunt Servanda" "Todo tratado en vigor obliga a las partes y debe ser cumplido por ellas de Buena fe". Es decir, que a partir del momento en que entra en vigor es fuente de derecho y las obligaciones internacionales que de él se derivan podrán ser exigidas al Estado parte; su incumplimiento constituirá violaciones, y por ende, generará responsabilidad internacional del Estado. (Reyes, 2007).

Por otra parte, la Corte Constitucional de Colombia (en adelante "Corte Constitucional") ha precisado que la jurisprudencia de las instancias internacionales de derechos

\footnotetext{
'Ver Ortiz, L. (2006). El proyecto de codificación en materia de tratados, fue adoptado como un tratado en la conferencia de Viena de 23 de mayo de 1969 con el nombre de Convención de Viena sobre el Derechos de los Tratados. El 21 de marzo de 1986 se circunscribe una segunda.
} 

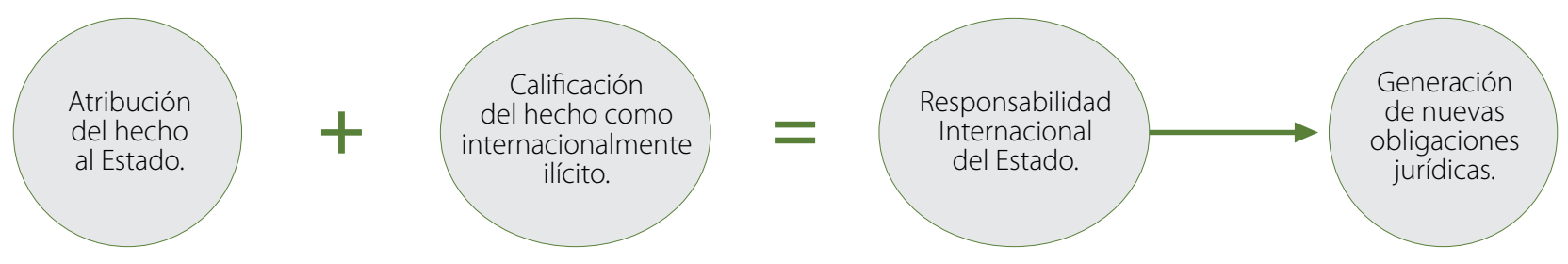

Figura 1. Concepto de Responsabilidad Internacional.

Fuente: Formación especializada en investigación, juzgamiento y sanción de violaciones a los derechos humanos y DIH (p. 22), por

Programa Presidencial de derechos humanos. Proyecto Lucha Contra la Impunidad- Fase-Il, 2010, Bogotá, Ediprime.

humanos constituye una pauta relevante para interpretar el alcance de los tratados sobre derechos humanos y, por ende, de los propios derechos constitucionales.

Los órganos e instituciones que profieren una interpretación autorizada de las normas de derechos humanos consolidan criterios que deben ser atendidos por el Estado colombiano en razón del principio de Buena fe en el cumplimiento de los tratados y en el marco de las obligaciones de respeto, protección y garantía frente a los derechos consagrados en el Derecho Internacional de los Derechos Humanos. Esta precisión tiene como fundamento, entre otros, el inciso segundo del artículo 93 de la Constitución Política de la República de Colombia de 1991.

Es de aclarar que los sistemas de protección regional y universal imputan responsabilidades al Estado, pero no establecen responsabilidades individualizadas. Estos tienen su origen en la Convención Europea de 1950, que servirá como modelo para que surjan posteriormente otros sistemas de protección a nivel universal y regional.

\section{El hecho internacionalmente ilícito del Estado}

Para Camargo (2013), la responsabilidad internacional es una institución de origen consuetudinario. En la actualidad, todo hecho internacionalmente ilícito del Estado genera su responsabilidad internacional respecto a sus obligaciones internacionales, por tanto, deriva una responsabilidad de carácter jurídico (p. 549). Aplicable a todo hecho internacionalmente ilícito del Estado cuando un comportamiento es consistente en una acción u omisión o en una combinación de ambas:

- Es atribuible al Estado según el derecho internacional (teoría de la imputación). Como ya sea referido el hecho ilícito debe ser real y efectivamente imputable a un Estado; análogamente, los Estados están obligados a respetar el orden jurídico internacional ${ }^{2} y$, en caso de violación, a restituir las

\footnotetext{
${ }^{2}$ Como ya se ha referido un Estado no puede, alegando que su
} actuación se encuentra ajustada a su ordenamiento interno, es- cosas a su estado normal o a reparar el daño causado con sus actos o hechos ilícitos.

- Constituye una violación de una obligación internacional sin importar que viole una disposición del derecho interno del Estado.

La calificación del hecho del Estado como internacionalmente ilícito se rige por el derecho internacional. Tal calificación no es afectada por la calificación del mismo hecho como lícito, por el derecho interno como está previsto en la Resolución aprobada sobre responsabilidad del Estado por hechos internacionalmente ilícitos. Como se expone en los principios generales OEA, A/RES/56/83, (2002).

De esta manera, resulta claro que las obligaciones internacionales tienen una variable de comportamiento determinante en la calificación del hecho como internacionalmente ilícito, que depende de dos elementos: en primer lugar de la identificación de la obligación primaria presuntamente violada y en segundo de las condiciones en que se realiza el hecho.

Para ilustrar, una violación a una obligación contenida en el Pacto Internacional de Derechos Económicos, Sociales y Culturales, tiene el carácter de una obligación de comportamiento, no puede ser valorada bajo los mismos presupuestos que la violación a la proscripción, a la amenaza o al uso de la fuerza como lo contiene el artículo 43 la Carta de Naciones Unidas de 1945. (ver Figura 1).

\section{Atribuciones de comportamiento al Estado}

El Estado será responsable por las conductas de sus órganos, como lo indica el artículo 4, contenido en OEA, A/ RES/56/83, (2002), en adelante RIE.

\section{Se considerará hecho del Estado según el de-}

capar a la caracterización que el derecho internacional haga del hecho como internacionalmente ilícito. Véase, Programa Presidencial de Derechos Humanos y DIH. (2010). 
recho internacional el comportamiento de todo órgano del Estado, ya sea que ejerza funciones legislativas, ejecutivas, judiciales o de otra índole, cualquiera que sea su posición en la organización del Estado y tanto si pertenece al gobierno central como a una división territorial del Estado.

2. Se entenderá que órgano incluye toda persona o entidad que tenga esa condición según el derecho interno del Estado.

Respecto del primer criterio de atribución de responsabilidad, es necesario identificar que a diferencia de los sistemas jurídicos internos en donde los órganos estatales son entidades jurídicas, algunas veces con personalidad jurídica y que por ende, pueden ser sujetos pasivos de acciones ante la jurisdicción, en el ámbito de la responsabilidad internacional del Estado, este, es valorado como una unidad. El principio de la unidad del Estado implica que, para los propósitos de la responsabilidad internacional, los actos y omisiones de sus órganos deben valorarse como actos y omisiones del Estado.

Es necesario indicar que el término "órgano" debe valorarse en su acepción más amplia. De esta forma, para efectos de la responsabilidad internacional, se extiende el concepto a todos los órganos del gobierno sin importar la función que desarrollen y sin importar que sean del orden nacional o territorial. Para la Corte Internacional de Justicia, esta concepción constituye una práctica generalmente admitida por los Estados como obligatoria.

El parágrafo segundo de este artículo, establece la posibilidad que tanto las personas como las entidades puedan valorarse como órganos del Estado para efectos de la responsabilidad internacional. Atendiendo al sentido amplio con el que se quiso definir el término "órgano", debe entenderse que cuando se habla de personas, se hace referencia tanto a las personas naturales como jurídicas.

Es decir, se evidencia la importancia del orden jurídico interno en la determinación del carácter de órgano de una entidad o persona. No obstante, muchas veces los ordenamientos locales no definen de manera exhaustiva qué personas o entidades tienen ese carácter, otras veces, el problema radica en que no se aplica el mismo criterio amplio que se utiliza en el derecho internacional. Por tal razón, ha sido entendido que para efectos de la responsabilidad internacional, un Estado no podrá oponer su derecho interno para negarle el carácter de órgano del Estado a una persona o entidad que en la realidad se comporta como tal.

Finalmente, para atribuir responsabilidad al Estado por la conducta de una persona que actúa como órgano del Estado, será necesario comprobar que dicha actuación representa, al menos en apariencia, una función oficial. De esta forma, será irrelevante que la persona haya actuado por fuera de sus capacidades o abusando de estas, si la conducta es desarrollada por la persona mientras actúa en calidad de órgano del Estado. Diferente será el caso en que pueda comprobarse que la persona desarrolló una conducta de carácter meramente privado.

\section{Obligaciones de respeto, protección y garantía}

Un deber manifiesta a su contenido obligacional específico. En este sentido, los deberes de respeto, garantía y adopción de medidas visibilizaban la obligación que sustantivamente debe desarrollar el Estado como obligado principal frente a los derechos humanos.

La responsabilidad del Estado ante el sistema interamericano se encuentra consagrada en las obligaciones internacionales derivadas de la Convención Americana a saber:

a. Respetar: no interfiriendo y obstaculizando directa o indirectamente, el goce de los derechos de la persona humana (hace referencia a los atributos inherentes a la dignidad humana) reconocidos en los tratados así como en los artículos 1 y 2 de la Convención; la Corte IDH, en su jurisprudencia Caso Velásquez Rodríguez Vs. Honduras. Sentencia de 29 de julio de 1988, párr. 165, establece que la primera obligación asumida por los Estados partes, es la de "respetar los derechos y libertades" reconocidos en la Convención, así el ejercicio de la función pública ${ }^{3}$ tiene unos límites que derivan de los derechos humanos como atributos inherentes a la dignidad humana $y$, en consecuencia, superiores al poder del Estado (Dulitzky, 2006, p.84).

Esta dimensión es ampliada por la Corte IDH, en Opinión Consultiva: OC-6/86 del 9 de mayo de 1986:

En efecto, la protección a los derechos humanos,

\footnotetext{
${ }^{3}$ Para ilustrar la definición de Función Pública: Las personas que prestan sus servicios profesionales retribuidos con vinculación legal y reglamentaria o contractual, en los organismos y entidades de la Administración Pública, conforman la función pública. Según la Ley de Empleo Público y Carrera Administrativa, hacen parte de la función pública los siguientes servidores públicos: empleados públicos de carrera, empleados públicos de libre nombramiento y remoción, empleados de periodo fijo, empleados temporales y trabajadores oficiales. Neira, J. (2008).
} 
CIENCIA Y PODER AÉREO | Revista Científica de la Escuela de Postgrados de la Fuerza Aérea Colombiana | Vol. 10 | Enero - Diciembre de 2015

en especial los derechos civiles y políticos recogidos en la Convención, parte de la afirmación de la existencia de ciertos atributos inviolables de la persona humana que no pueden ser legítimamente menoscabados por el ejercicio del poder público. Se trata de esferas individuales que el Estado no puede vulnerar o en las que sólo puede penetrar limitadamente. Así, en la protección a los derechos humanos, está necesariamente comprendida la noción de la restricción al ejercicio del poder estatal (párr. 21).

Así la obligación de respetar comprende el deber del Estado de no inmiscuirse en el ámbito privado de las relaciones personales de los gobernados, mediante acciones arbitrarias o ilegítimas. La Constitución de 1991 desarrolla esta obligación a través de las Ilamadas cláusulas generales de respeto a los atributos inherentes a la dignidad humana como lo confirma el artículo 1, a la vida el artículo 11 y a la libertad el artículo 28 entre otros de la Constitución Política de Colombia de 1991.

Artículo 1. Colombia es un Estado social de derecho, organizado en forma de República unitaria, descentralizada, con autonomía de sus entidades territoriales, democrática, participativa y pluralista, fundada en el respeto de la dignidad humana, en el trabajo y la solidaridad de las personas que la integran y en la prevalencia del interés general.

Artículo 11. El derecho a la vida es inviolable. No habrá pena de muerte.

Artículo 28. Toda persona es libre. Nadie puede ser molestado en su persona o familia, ni reducido a prisión o arresto, ni detenido, ni su domicilio registrado, sino en virtud de mandamiento escrito de autoridad judicial competente, con las formalidades legales y por motivo previamente definido en la ley.

b. Proteger: adoptando las medidas requeridas a través de la ley, de un efectivo aparato judicial y aparato administrativo "adopción de disposiciones internas pero no limitadas" para que otros (terceros o a través de funcionarios, instituciones o políticas distintos al Estado) no interfieran en el disfrute de los derechos protegidos de las personas que se encuentren en su territorio y estén sujetos a su jurisdicción.

Tal como se describe en la Convención Interamericana en el artículo 2. Deber de adoptar disposiciones de derecho interno:

Si el ejercicio de los derechos y libertades mencionados en el artículo 1 no estuviere ya garantizado por disposiciones legislativas o de otro carácter, los Estados Partes se comprometen a adoptar, con arreglo a sus procedimientos constitucionales y a las disposiciones de esta Convención, las medidas legislativas o de otro carácter que fueren necesarias para hacer efectivos tales derechos y libertades (s. p.)

Respecto a este artículo la Corte IDH indicó según Sentencia, Caso Velásquez Rodríguez Vs. Honduras que conforme al artículo 1.1 de la Convención, es ilícita toda forma de ejercicio del poder público que viole los derechos reconocidos por la Convención. Es decir, en toda circunstancia en la cual un órgano o funcionario del Estado o de una institución de carácter público lesione indebidamente uno de los derechos, se está ante un supuesto de inobservancia del deber de respeto consagrado en ese artículo (párr.169).

Por el contrario, es independiente que el órgano o funcionario haya actuado en contravención de disposiciones del derecho interno o desbordado los límites de su propia competencia, puesto que es un principio de derecho internacional que el Estado responda por los actos de sus agentes realizados al amparo de su carácter oficial y por las omisiones de los mismos aún si actúan fuera de los límites de su competencia o en violación del derecho interno (párr. 170).

c. Garantizar: a saber adoptando las medidas apropiadas de carácter legislativo, administrativo, presupuestario, judicial o de otra índole que permitan el disfrute efectivo de los derechos protegidos y reconocidos por la Convención a toda persona sujeta a su jurisdicción, como un ideal común de los pueblos.

En este sentido, la Corte IDH indica, que esta obligación implica el deber de los Estados Partes de organizar todo el aparato gubernamental, incorporando para el caso, otras obligaciones de facilitar, proporcionar y promover las medidas suficientes para dar plena efectividad a los derechos humanos. Este deber tiene directa relación con el derecho que tiene la persona humana a acciones positivas del Estado, así como, a la organización del aparato estatal, el despliegue y las políticas nacionales. De manera que se asegure el pleno ejercicio de los derechos humanos, en este sentido considérese el Marco Constitucional:

La Constitución de 1991 estableció un Estado

98 | La responsabilidad internacional del Estado colombiano ante la Corte Interamericana de Derechos Humanos por la inoperancia de la justicia interna. 
Social de Derecho garantista de los DDHH en Colombia. El país es hoy una democracia que elige popularmente a sus gobernantes y representantes, tanto en los niveles locales como en el nivel nacional, y existe una pluralidad de partidos políticos que cuenta con amplias garantías. En el Congreso de la República hay 10 partidos representados y ninguno ostenta más del $20 \%$ de las curules. La democracia se ejerce a través de tres ramas del poder público independientes y un conjunto de organismos de control. Adicionalmente, existen importantes herramientas para ejercer la democracia directa, como la posibilidad de adelantar referendos e iniciativas legislativas populares. La Constitución contiene además un fecundo catálogo de derechos fundamentales con efectivos mecanismos de protección, los cuales han propiciado importantes avances jurisprudenciales. Colombia es uno de los Estados que más tratados internacionales de DDHH y DIH ha ratificado, tanto del Sistema Universal como del Sistema Interamericano de DDHH (SIDH). Estos 61 tratados hacen parte integral de la Constitución de tal manera que cualquier norma que los contradiga debe ser declarada inconstitucional. Como lo señala el Informe Nacional presentado de conformidad con el párrafo 15.a. Anexo a la Resolución 5/1 del Consejo de Derechos Humanos (OEA, 2006, párr. $11,12,13$ y 14$)$

Es decir, la estructura de organización del aparato estatal $y$, en general, todas las estructuras ${ }^{4}$ a través de las cuales se manifiesta el ejercicio del poder público al res-

\footnotetext{
${ }^{4}$ Verbigracia, El Secretario de Naciones Unidas indicó que el Gobierno había reconocido la necesidad de reformar la Ley de justicia y paz (No 975), que continuaba sin satisfacer los derechos de las víctimas, garantizar la no repetición, ni lograr la aplicación del derecho a la verdad. Este se refirió a la reforma constitucional de julio de 2012 denominada "Marco jurídico para la paz" a través de la cual se otorgan al Presidente facultades de justicia transicional para emprender procesos de paz con el objeto de facilitar la terminación del conflicto armado interno y garantizar los derechos de las víctimas. Además se prevé la creación de una Comisión de la Verdad. El Grupo de Trabajo sobre las Desapariciones Forzadas o Involuntarias expresó su preocupación por dicha reforma constitucional que habilitaría a las autoridades para renunciar a la persecución penal o suspender la ejecución de la pena en casos de graves violaciones de derechos humanos, crímenes de lesa humanidad y crímenes de guerra. Organización de Naciones Unidas. Recopilación preparada por la Oficina del Alto Comisionado para los Derechos Humanos con arreglo al párrafo 5 del Anexo de la Resolución 16/21 del Consejo de Derechos Humanos. Colombia. A/HRC/WG.6/16/COL/2 Ginebra, 22 de abril a 3 de mayo de 2013, párr. 11.
}

pecto se admite:

Son Ramas del Poder Público, la legislativa, la ejecutiva, y la judicial. Además de los órganos que las integran existen otros, autónomos e independientes, para el cumplimiento de las demás funciones del Estado. Los diferentes órganos del Estado tienen funciones separadas pero colaboran armónicamente para la realización de sus fines. Constitución Política de Colombia, (2009, art. 113).

Por lo tanto, sean capaces de asegurar jurídicamente el libre y pleno ejercicio de los derechos humanos. Como consecuencia de esta obligación los Estados deben prevenir, investigar y sancionar toda violación de los derechos reconocidos por la Convención y procurar, además, el restablecimiento integral, si es posible, del derecho conculcado y, en su caso, la reparación de los daños producidos por la violación de los derechos humanos.

La obligación de reparación íntegra acoge diferentes formas, las cuales, pueden ser únicas o concurrentes: de restitución, de indemnización y de satisfacción como lo contiene el artículo 34 de la OEA, Resolución aprobada por la Asamblea General [sobre la base del informe de la Sexta Comisión (A/56/589 y Corr.1)] 56/83. 85ª sesión plenaria del 12 de diciembre de 2001.

Al anterior argumento se agrega que la obligación de garantizar el libre y pleno ejercicio de los derechos humanos por parte de los Estados partes, debe estar manifiesta en la vigencia de su establecimiento, en la observancia y defensa de los derechos humanos, no se agota con la existencia de un orden normativo dirigido a hacer posible el cumplimiento de esta obligación, sino que comparte la necesidad de una conducta gubernamental verdadera y efectiva que asegure la existencia, en la realidad, de una eficaz garantía del libre y pleno ejercicio de los derechos humanos.

Por su parte, la Escuela Judicial Rodrigo Lara Bonilla (2008, pp. 173-174) examina intensamente el deber de garantía y lo desagrega en las siguientes obligaciones:

1. La obligación de garantizar el pleno y libre ejercicio de los derechos y las libertades reconocidos sin discriminación alguna.

2. El deber del Estado de prevenir las violaciones de los derechos humanos. En este punto, la doctrina ha distinguido las siguientes obligaciones:

- Deber de normar.

- Deber de hacer seguimiento. 
CIENCIA Y PODER AÉREO | Revista Científica de la Escuela de Postgrados de la Fuerza Aérea Colombiana | Vol. 10 | Enero - Diciembre de 2015

- Deber de llevar a cabo estudios de impacto.

- Deber de eliminar los obstáculos estructurales.

3. El deber del Estado de investigar las violaciones de los derechos humanos, lo cual compromete a los Estados con remover los obstáculos a la labor de la justicia que conduzcan a la impunidad. Al respecto la Corte IDH en su jurisprudencia Caso Velásquez Rodríguez Vs Honduras indica:

El Estado, está por otra parte obligado a investigar toda situación en la que se hayan violado los derechos humanos protegidos por la Convención. Si el aparato del Estado actúa de modo que, tal violación quede impune y no se restablezca, en cuanto sea posible, a la víctima en la plenitud de sus derechos, puede afirmarse que ha incumplido el deber de garantizar su libre y pleno ejercicio a las personas sujetas a su jurisdicción. Lo mismo es válido cuando se tolere que los particulares o grupos de ellos actúen libre o impunemente en menoscabo de los derechos humanos reconocidos en la Convención (párr. 169).

4. El deber de sancionar dichas violaciones. La obligación de sancionar implica, según la jurisprudencia constante de la Corte IDH, que el Estado tiene "la obligación de sancionar a los responsables" de violaciones a los derechos humanos como Galvis y Salazar (2007) lo argumentan respecto de la relación de complementariedad con la Convención Interamericana de Desaparición Forzada de Personas y contenida en el artículo 6 "Con relación a la investigación y juzgamiento (en el derecho interno se refiere a los autores materiales e intelectuales), la Convención establece que cuando el presunto responsable de una desaparición forzada está en el territorio de un Estado parte y éste no conceda la extradición, "someterá el caso a sus autoridades competentes como si el delito se hubiere cometido en el ámbito de su jurisdicción, para efectos de la investigación y, cuando corresponda, de proceso penal".

5. El deber del Estado de restablecer y reparar, cuando no sea posible restaurar el derecho violado como lo considera la Corte IDH el artículo 63.2 presentando las obligaciones de reparación

6. El deber de asegurar un contenido esencial (Robert, 1993). Cabe anotar que según la teoría positivista el contenido esencial se vincula a la protección normativa de los intereses defendidos por el derecho, mirando siempre a la tutela de la voluntad o autonomía individual frente a posibles intromisiones del Estado. En cualquier caso el contenido esencial desempeña un importante papel a la hora de interpretar los derechos. En este sentido el legislador a la hora de interpretar el significado de los derechos, es decir, a la hora de legislar sobre los derechos, va a tener como límite la cláusula del contenido esencial, ésta opera como límite de la actuación interpretativa. Además, aunque la cláusula parezca estar referida a la legislación, incide también en la actuación de los restantes operadores jurídicos (León, 2010, p. 54). Por todo lo anterior, se puede considerar que el contenido esencial es el límite de las limitaciones, respecto a esto en el derecho interno la Corte Constitucional considera que existe una violación a las obligaciones internacionales si el Estado no asegura este mínimo vital del derecho, salvo que existan poderosas razones que justifiquen el incumplimiento:

[...] No podrá restringirse o menoscabarse ninguno de los derechos reconocidos o vigentes en un Estado en virtud de su legislación interna o de convenciones internacionales, invocando como pretexto que el presente Protocolo no los reconoce o los reconoce en menor grado. Esta regla interpretativa ha sido denominada por la doctrina como la cláusula de favorabilidad en la interpretación de los derechos humanos, según la cual, en caso de conflictos entre distintas normas que consagran o desarrollan estos derechos, el intérprete debe preferir aquella que sea más favorable al goce de los derechos. Colombia, Corte Constitucional, Sentencia (C-251 de 1997).

En conclusión, la obligación de respetar y garantizar exige remover obstáculos que, a pesar de no basarse en normas internas, surgen de la estructura y culturas sociales.

\section{Inoperancia de la justicia interna}

En este orden, como Ramelli (2004) lo indica, es función del Congreso de la República desarrollar las competencias legislativas requeridas para adoptar las normas internacionales frente a la tesis de una legalidad internacional, mediante una configuración normativa complementaria, que permita la aplicabilidad de las normas del derecho internacional y el derecho internacional humanitario desde una pura y técnica perspectiva jurídico-internacional a través del bloque de constitucionalidad. 
Llama la atención dentro de este marco que el bloque de constitucionalidad, es uno de los más importantes aportes de la Constitución de 1991 en el sistema jurídico colombiano. Su función fundamental es la de servir como instrumento de recepción del derecho internacional, garantizando la coherencia de la legislación interna con los compromisos ad extra del Estado y al mismo tiempo, servir de complemento para la garantía de los derechos humanos y el derecho internacional humanitario en el país (Fajardo, 2007).

Para el caso la normatividad 5 actual referente a la prelación de los Tratados según la Ley 906 de 2005 manifiesta en el artículo 3: [...] En la actuación prevalecerá lo establecido en los tratados y convenios internacionales ratificados por Colombia que traten sobre derechos humanos y que prohíban su limitación durante los estados de excepción, por formar bloque de constitucionalidad.

Análogamente, este ámbito normativo se extiende y deriva en un derecho humano esencial como lo contiene el artículo 228: la administración de justicia es una función pública. Sus decisiones son independientes. Las actuaciones son públicas y permanentes, con las excepciones que establezca la ley y en ellas prevalecerá el derecho sustancial. Los términos procesales se observarán con diligencia y su incumplimiento será sancionado. Su funcionamiento será desconcentrado y autónomo, Constitución Política de Colombia de 2009.

La Corte Constitucional de la República de Colombia, en Sentencia No. C-029/95, expresa que cuando el artículo 228 de la Constitución establece que en las actuaciones de la administración de justicia "prevalecerá el derecho sustancial", está reconociendo que el fin de la actividad jurisdiccional, y del proceso, es la realización de los derechos consagrados en abstracto por el derecho objetivo, y, por consiguiente, la solución de los conflictos de intereses. Es evidente que en relación con la realización de los derechos y la solución de los conflictos, el derecho procesal, y específicamente el proceso, es un medio.

Sin embargo, el artículo 229 garantiza el derecho de toda persona para acceder a la administración de justicia. La ley indicará en qué casos podrá hacerlo sin la representación de abogado.

\footnotetext{
${ }^{5}$ Para profundizar pueden verse siguientes concordancias: Constitución Política; Art. 44; Art. 93 y Art. 94; Ley 941 de 2005 Art. 10; Ley 906 de 2004 Art. 124 y Art. 130 y Ley 600 de 2000 Art. 2. Jurisprudencia concordante: Corte Constitucional de la República de Colombia, Sentencia C-760-01 de 18 de julio de 2001.
}

Bajo este mandato, corresponde identificar los respectivos órganos judiciales del Estado responsables de prever lo descrito en las obligaciones y estándares internacionales de justicia, así como garantizar la reparación. La referencia de obligaciones incluye deberes positivos y negativos descritos en los artículos 1.3, 55.c., y 56 de la Carta de las Naciones Unidas (1945), que impone a todos los estados miembros la obligación de promover el respeto universal de los derechos humanos y las libertades fundamentales de todas las personas como seres humanos, sin hacer distinción de raza, sexo, idioma o religión, y la efectividad evolutiva de estos derechos y libertades, tanto, en el marco internacional como en el marco nacional de los derechos humanos.

\section{Órganos judiciales del Estado}

Es este contexto, es importante considerar que la máxima representatividad del Estado son sus instituciones, luego si se agotan sus instituciones se agota el Estado. En el marco de aplicabilidad de los estándares internacionales no se habla de personas sino de procesos, para el caso, la administración de justica es el macro proceso de la realidad jurídica aplicable, adjunto a sus micro procesos, en donde, se genera la verificación constitucional de respeto, protección y garantía de los derechos humanos con las debidas precauciones, para interpretar el alcance de los ámbitos normativos. Estos micros procesos son:

- Las Altas Cortes y sus Jurisdicciones (ordinaria, disciplinaria, constitucional, contencioso administrativa) e inclusive las especiales (conformadas por los jueces de paz, militar, las comunidades indígenas y mecanismos o alternativas de solución de conflictos).

- Fiscalía General de la Nación. En el artículo 250 de la Constitución Política de Colombia de 2009, se exponen las funciones y responsabilidades del ente institucional.

- Ministerio Público. Encargado de intervenir en el proceso penal cuando sea necesario, en defensa del orden jurídico, del patrimonio público, o de los derechos y garantías fundamentales según artículo 109, Ley 906 de 2005.

A continuación, la perspectiva general del macro proceso de Administración de Justicia (Figura 2). 
CIENCIA Y PODER AÉREO | Revista Científica de la Escuela de Postgrados de la Fuerza Aérea Colombiana | Vol. 10 | Enero - Diciembre de 2015

Tabla 1. Síntesis de las sentencias emitidas por la Corte IDH al Estado Colombiano.

\begin{tabular}{|c|c|c|c|c|c|c|c|c|}
\hline \multirow[b]{2}{*}{ Contenciosos } & \multirow[b]{2}{*}{ Derechos violados } & \multirow{2}{*}{$\begin{array}{l}\text { Grado de } \\
\text { Responsabilidad } \\
\text { del Estado }\end{array}$} & \multirow[b]{2}{*}{ Histórico } & \multirow{2}{*}{ 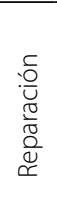 } & \multirow{2}{*}{ 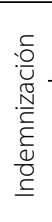 } & \multicolumn{3}{|c|}{$\begin{array}{l}\text { Justicia } \\
\text { Interna } \\
\end{array}$} \\
\hline & & & & & & 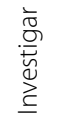 & $\begin{array}{l}\stackrel{\overline{0}}{D} \\
\stackrel{N}{\beth}\end{array}$ & 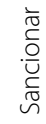 \\
\hline $\begin{array}{l}\text { Caso Rodríguez Vera y otros (Desaparecidos del Palacio } \\
\text { de Justicia) Vs. Colombia. } \\
\text { Sentencia de } 14 \text { de noviembre de 2014. Serie C No. } 287\end{array}$ & $\begin{array}{c}\text { Art.3,4,4.1,5.1,5.2,6,7.1,7.2 } \\
, 8,11.1,11.2,8.1 \text { y } 25.1^{* * *} \\
\text { Art.1.1 }\end{array}$ & Art. 1.1 Rp* & $\begin{array}{l}6 \text { y } 7 \text { de } \\
\text { noviembre de } \\
1985 \text {. }\end{array}$ & $x$ & $x$ & $x$ & $x$ & $x$ \\
\hline $\begin{array}{c}\text { Caso de las Comunidades Afrodescendientes Desplaza- } \\
\text { das de la Cuenca del Río Cacarica (Operación Génesis) } \\
\text { Vs. Colombia. } \\
\text { Sentencia de } 20 \text { de noviembre de 2013. Serie C No. } 270\end{array}$ & $\begin{array}{c}\text { Art. } 4.1 \text { y } 5.1 / 5.2^{* * *} \text { Art. } 1.1 \\
\text { Art.5,11,17,19,21,24*** } \\
\text { Art.19 } \\
\text { Art. } 8 \text { y } 25^{* * *} \text { Art. } 1.1 \\
\text { Art. } 21^{* * *} \text { Art 25.2.a y } 25.2 . \mathrm{C}\end{array}$ & Art. 1.1 Rp* & $\begin{array}{c}24 \text { y el } 27 \text { de } \\
\text { febrero de } 1997\end{array}$ & $x$ & $x$ & $x$ & $x$ & $x$ \\
\hline $\begin{array}{l}\text { Caso Masacre de Santo Domingo Vs. Colombia. } \\
\text { Sentencia de } 19 \text { de agosto de 2013. Serie C No. } 263 \text {. } \\
\text { Sentencia de } 30 \text { de noviembre de 2012. Serie C No. } 259\end{array}$ & $\begin{array}{c}\text { Art.2.1,4.1,5.1,8 y } \\
25^{* * *} \text { Art.1.1 } \\
\text { Art.5.1 y } 1.1^{* * *} \text { Art.22.1 } \\
\end{array}$ & $\begin{array}{l}\text { Art. } 1.1 \mathrm{Rp}^{*} \\
\text { No Aplica }\end{array}$ & $\begin{array}{l}13 \text { de diciem- } \\
\text { bre de } 1998\end{array}$ & $x$ & $x$ & $x$ & $x$ & $x$ \\
\hline $\begin{array}{l}\text { Caso Vélez Restrepo y Familiares Vs. Colombia. } \\
\text { Sentencia de } 3 \text { de septiembre de } 2012 \text { Serie C No. } 248\end{array}$ & $\begin{array}{c}\text { Art.5.1,8.1,13,17.1,22,1 y } \\
25^{* * *} 1.1 \\
\text { Art.19 }\end{array}$ & Art. 1.1 Rp* & $\begin{array}{l}29 \text { de agosto } \\
\text { de } 1996\end{array}$ & $x$ & $x$ & $x$ & $x$ & $x$ \\
\hline $\begin{array}{l}\text { Caso Manuel Cepeda Vargas Vs. Colombia. } \\
\text { Sentencia de } 26 \text { de mayo de 2010. Serie C No. } 213\end{array}$ & $\begin{array}{c}\text { Art.4.1,5.1,8.1,11,13.1,16,23 } \\
\text { y } 25^{* * *} \text { Art.1.1 }\end{array}$ & Art. 1.1 Rt** & $\begin{array}{l}9 \text { de agosto de } \\
1994\end{array}$ & $x$ & $x$ & $x$ & $x$ & $x$ \\
\hline $\begin{array}{l}\text { Caso Valle Jaramillo y otros Vs. Colombia. } \\
\text { Sentencia de } 7 \text { de julio de } 2009 \text { Serie C No. 201.Senten- } \\
\text { cia de } 27 \text { de noviembre de 2008. Serie C No. } 192\end{array}$ & $\begin{array}{l}\text { Art.4.1,5.1,7.1,8.1,22.1 y } \\
\text { 25.1 }{ }^{* * *} \text { Art.1.1 }\end{array}$ & Art. 1.1 Rp* & $\begin{array}{l}27 \text { de febrero } \\
\text { de } 1998\end{array}$ & $x$ & $x$ & $x$ & $x$ & $x$ \\
\hline $\begin{array}{l}\text { Caso Escué Zapata. Vs. Colombia. } \\
\text { Sentencia de } 5 \text { de mayo de } 2008 \text { Serie C No. 178.Senten- } \\
\text { cia de } 4 \text { de julio de 2007. Serie C No. } 165\end{array}$ & $\begin{array}{c}\text { Art.4,5.1,5.2,7.1,7.2,11.2,8.1 } \\
\text { y } 25^{* * *} \text { Art.1.1 }\end{array}$ & Art. 1.1 Rp* & $\begin{array}{l}01 \text { de febrero } \\
\text { de } 1988\end{array}$ & $x$ & $x$ & $x$ & $x$ & $x$ \\
\hline $\begin{array}{l}\text { Caso de la masacre de La Rochela Vs. Colombia. } \\
\text { Sentencia de } 28 \text { de enero de } 2008 \text { Serie C No. 175.Sen- } \\
\text { tencia de } 11 \text { de mayo de 2007. Serie C No. } 163\end{array}$ & $\begin{array}{l}\text { Art. } 4,5,5.1,5.2,8.1 \text { y } 25 * \\
\text { Art. } 1.1\end{array}$ & Art. 1.1 Rp & $\begin{array}{l}18 \text { de enero de } \\
1989\end{array}$ & $x$ & $x$ & $x$ & $x$ & $x$ \\
\hline $\begin{array}{l}\text { Caso de la Masacre de Pueblo Bello Vs. Colombia. } \\
\text { Sentencia de } 25 \text { de noviembre de 2006. Serie C No. } 159 . \\
\text { Sentencia de } 31 \text { de enero de 2006. Serie C No. } 140\end{array}$ & $\begin{array}{l}\text { Art.4.1,5.1,5.2,7.1,7.2,8.1 y } \\
\text { 25 }{ }^{* * *} \text { Art.1.1 }\end{array}$ & $\begin{array}{l}\text { No se } \\
\text { consigna }\end{array}$ & $\begin{array}{c}13 \text { y } 14 \text { de } \\
\text { enero (año sin } \\
\text { precisar) }\end{array}$ & $x$ & $x$ & $x$ & $x$ & $x$ \\
\hline $\begin{array}{l}\text { Caso de las Masacres de Ituango Vs. Colombia. } \\
\text { Sentencia de } 1 \text { de julio de } 2006 \text { Serie C No. } 148\end{array}$ & $\begin{array}{c}\text { Art4,5,6,6.2,7,11.2,21,22,8 y } \\
25^{* * *} \text { Art. } 1.1\end{array}$ & Art. 1.1 Rp* & $\begin{array}{l}11 \text { de junio de } \\
1996,22 \text { de } \\
\text { octubre y } 12 \\
\text { de noviembre } \\
\text { de } 1997\end{array}$ & $x$ & $x$ & $x$ & $x$ & $x$ \\
\hline $\begin{array}{l}\text { Caso de la"Masacre de Mapiripán"Vs. Colombia. } \\
\text { Sentencia de } 15 \text { de septiembre de 2005. Serie C No. } 134 . \\
\text { Sentencia } 7 \text { de marzo 2005. Serie C No. } 122\end{array}$ & $\begin{array}{c}\text { Art.4.1,5.1,5.2,7.1,7.2,22.1,19 } \\
\text { y } 11,8.1 \text { y } 25^{* * *} \text { Art. } 1.1\end{array}$ & Art. 1.1 Rp & $\begin{array}{l}12,15 \text { y } 22 \text { de } \\
\text { julio de } 1997\end{array}$ & $x$ & $x$ & $x$ & $x$ & $x$ \\
\hline $\begin{array}{l}\text { Caso Gutiérrez Soler Vs. Colombia. } \\
\text { Sentencia de } 12 \text { de septiembre de 2005. Serie C No. } 132 .\end{array}$ & $\begin{array}{c}\text { Art.1,5.1,5.2,5.4,6,7.1,7.2,7. } \\
3,7.4,7.5,7.6,8.1,8.2 \mathrm{~d}, 8.2 \mathrm{e}, 8 . \\
2 \mathrm{~g}, 8.3,8 \text { y } 25^{* * *} \text { Art. } 1.1\end{array}$ & Art. 1.1 Rp & $\begin{array}{l}24 \text { de agosto } \\
\text { de } 1994\end{array}$ & $x$ & $x$ & $x$ & $x$ & $x$ \\
\hline $\begin{array}{l}\text { Caso } 19 \text { Comerciantes Vs. Colombia. Fondo, Repara- } \\
\text { ciones y Costas. } \\
\text { Sentencia de } 5 \text { de julio de 2004. Serie C No. 109.Senten- } \\
\text { cia de } 12 \text { de junio de 2002. Serie C No. } 93\end{array}$ & Art.4,5,7,8.1 y $25^{* * *}$ Art.1.1 & Art. $1.1 \mathrm{Rt}^{* *}$ & $\begin{array}{l}7 \text { de octubre } \\
\text { de } 1987\end{array}$ & $x$ & $x$ & $x$ & $x$ & $x$ \\
\hline $\begin{array}{l}\text { Caso Las Palmeras Vs. Colombia. Reparaciones y Costas. } \\
\text { Sentencia de } 26 \text { Noviembre de 2002. Serie C No. } 96 . \text { Sen- } \\
\text { tencia de } 4 \text { de febrero de 2000. Serie C No. } 67\end{array}$ & Art.4,8.1 y $25^{* * *}$ Art.1.1 & Art. $1.1 \mathrm{Rt}^{* *}$ & $\begin{array}{l}23 \text { de enero de } \\
1991\end{array}$ & $x$ & $x$ & $x$ & $x$ & $x$ \\
\hline $\begin{array}{l}\text { Caso Caballero Delgado y Santana Vs. Colombia. Repara- } \\
\text { ciones y Costas. } \\
\text { Sentencia de } 29 \text { de enero de 1997. Serie C No. 31.Sen- } \\
\text { tencia de } 8 \text { de diciembre de 1995. Serie C No. 22.Senten- } \\
\text { cia de } 21 \text { de enero de 1994. Serie C No. } 17\end{array}$ & Art. 4 y $7^{* * *}$ Art.1.1 & $\begin{array}{l}\text { No se } \\
\text { consigna }\end{array}$ & $\begin{array}{l}7 \text { de febrero de } \\
1989\end{array}$ & $x$ & $x$ & $x$ & $x$ & $x$ \\
\hline
\end{tabular}

Los textos íntegros de las Sentencias. *Responsabilidad parcial, **Responsabilidad total, **Relación con otro artículo de la Convención. Fuente: elaboración de la autora. 


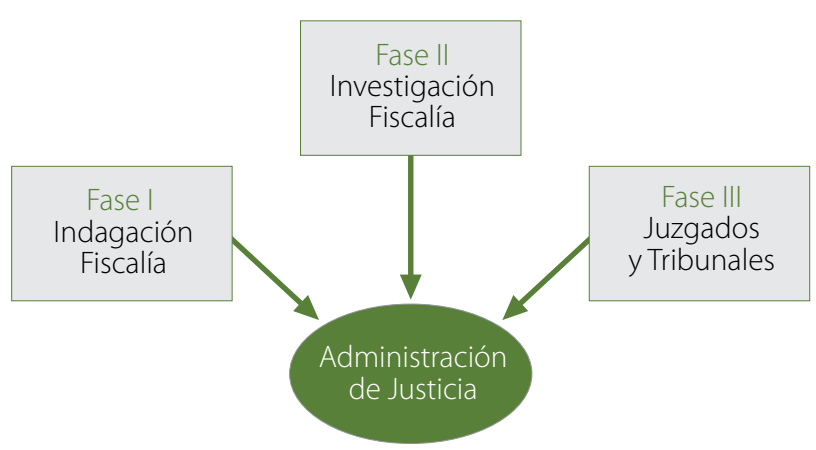

Figura 2. Estructura de la Administración de Justicia.

Fuente: elaboración de la autora.

\section{Formulación explicativa}

En este orden de ideas, es necesario, identificar ¿Cuál es el patrón que incide en el aumento de los casos emitidos en sentencia por la Corte IDH, como resultado de las violaciones a los estándares que contempla el Derecho Internacional de los Derechos Humanos?

Si bien es cierto, las sentencias en proceso del Estado colombiano ante la Corte IDH, reflejan una situación compleja en la justicia interna, en una ausente dinámica procesal, no abarcando la dimensión internacional de los derechos humanos que comprende una problemática de carácter integral, en el sentido de garantizar la eficacia en la aplicación adecuada de las medidas administrativas, legislativas y judiciales a través de la expansión y cobertura en la Administración de Justicia.

Se ha observado en hechos representativos y en la situación de determinadas víctimas, la ejecución, la tortura y la desaparición de determinadas personas, en función del contexto de violaciones masivas y sistemáticas de derechos humanos; en la actualidad y en numerosas situaciones, estos hechos particulares se enmarcan en patrones de discriminación y violencia contra grupos o sectores sociales determinados. En la Tabla No 1 se han registrado las variables individuales y colectivas como causa, en el grado de responsabilidad del Estado colombiano, ante las sentencias emitidas por la Corte IDH:

La aplicación que ofrecen los anteriores registros, sugieren procurar el equilibrio, donde se capturan patrones de solución en función de su afectación y frecuencia; no principios o estrategias abstractas; es decir, la situación de determinadas víctimas observada desde la perspectiva de la Corte IDH, identifica y reconoce un vínculo entre el Estado y los hechos determinados a repetitividad, lo cual demanda en términos específicos realizar una detección y análisis de perfiles radicales respecto de los niveles de res- ponsabilidad y funcionabilidad en lo penal y lo disciplinario en la Estructura de la Administración de Justicia.

\section{Teoría de Nash}

En un sentido complementario a lo anterior, la teoría de juegos introduce el concepto llamado Equilibrio de Nash, estudia las situaciones en las que tanto las acciones como los resultados derivados de ellas dependen de las acciones que otros puedan llevar a cabo. Es decir, se genera un efecto de interdependencia estratégica (varias estrategias), para determinar cuáles son las acciones que los distintos individuos pueden llevar a cabo teniendo en cuenta el grado de conocimiento del que se dispone en cada variable; en otras palabras, nadie tiene incentivos individuales para variar la estrategia a no ser que se realicen acuerdos de carácter dominante.

Corresponde entonces cualitativa e individualmente en el razonamiento al reconocimiento de la variable CP = Criterio Profesional; esto no debería limitar el alcance de las situaciones contractuales, utilizadas por los órganos macro y micro del Estado, ya que proporcionaría el método de orientación a la hora de determinar el equilibrio entre lo simple y lo complejo desde la competencia profesional (educación, formación, habilidades y experiencia en el Standard Internacional) permitiendo constituir la base del patrón de identificación en mecanismos de seguimiento, monitoreo y control; formulados con criterios alternativos, rápidos, confiables y económicos; conducentes eficientemente a las Fases I y || en su orden de Indagación e Investigación.

Este esfuerzo, debe propender, por el equilibrio de una justicia clara y evidente, para el caso representada en la segunda variable cualitativa y colectiva, $T=$ Transparencia, lo que debería asegurar la dinámica del proceso judicial en lo respecta a investigar, juzgar y sancionar. Lo anterior, permite tener la capacidad de identificar lo simple de lo complejo, generando informes independientes en cada caso de violación: deben ser transparentes y basarse exclusivamente en criterios profesionales (normas de conducta profesional, éxitos académicos y profesionales), aportando los elementos suficientes que permitan desvirtuar los hechos denunciados y perfeccionar las fases de indagación e investigación; para esclarecer las circunstancias y responsabilidades a que haya lugar. Además de hacer un uso adecuado de los recursos que promuevan las prioridades de las jurisdicciones locales y satisfacer las necesidades de sus comunidades.

En detalle las variables CP y T en su posición, indican una mutua relación en el orden de categorización individual y colectivo, así el criterio profesional es procedente si se comprende individualmente, luego en la amplitud de la 
CIENCIA Y PODER AÉREO | Revista Científica de la Escuela de Postgrados de la Fuerza Aérea Colombiana | Vol. 10 | Enero - Diciembre de 2015

unidad de observación, la colectividad nominal corresponde a un efecto vital de interdependencia estratégica.

Respecto de los acuerdos de carácter dominante se encuentran dos supuestos: los cooperativos y los no competitivos, esto traduce el factor nominal de aplicación y ejecución en virtud de los supuestos en la actuación. Así un proceso penal y/o disciplinario ausente de criterio profesional, excede el control de tolerancia (grado de responsabilidad) en cualquiera de las fases de la Administración de Justicia. Lo cual indica emprender una cuidadosa acción correctiva de carácter inmediato previa verificación en la acción de la gestión.

Ahora bien, si la variable CP obedece a ser efectiva compensara su actuación de equilibrio en cooperación con la variable T. Luego si CP Y T son cooperativas favorecerán el equilibrio de estos supuestos, aplicables en las fases de indagación, investigación y juzgamiento al momento de identificar, juzgar y sancionar a todos los autores materiales e intelectuales de las violaciones cometidas en perjuicio de las víctimas.

El modelo matricial No. 1 (ver Tabla 2) ilustra una estrategia pura, en donde, cada una de las Fases de indagación e investigación, podría mejorar su situación, si se elimina una mutua defección, tanto para lo simple como para lo complejo, ya que provocaría una entrega peor (ni lo complejo, ni lo simple, es relevante) que el de una cooperación, como se puede inferir en la contraprestación, se evoca por una cooperación unilateral. Es decir, cada fase realiza una combinación de estrategias, si cada fase, puede producir un beneficio común, para los dos casos, el simple o el complejo, el complejo o el simple; si una de las fases puede producir este beneficio común, no tiene ningún sentido que la otra fase duplique sus esfuerzos, el equilibrio de Nash es entonces evidente, si, se varían las estrategias para cooperar conjuntamente como meta clara; pero la estrategia elegida no es óptima, ya que una fase copera y la otra no coopera, como se puede ver en la matriz de entrega No 1. Si en lo simple no se es cooperativo mucho menos en lo complejo, luego la perfección de los procesos radica en hacer bien las operaciones de composición más simples (pequeñas).

Tabla 2. Modelo Matricial No 1. *Simple, ${ }^{* *}$ Complejo.

\begin{tabular}{|c|c|c|c|}
\hline \multirow{2}{*}{$\mathrm{S}_{*}$} & & \multicolumn{2}{|c|}{ Investigación } \\
\hline & \multicolumn{3}{|c|}{$C_{* *}$} \\
\hline \multirow{2}{*}{ Indagación } & $S$ & $3: 3$ & $1: 6$ \\
\hline & C & $6: 1$ & $1: 1$ \\
\hline
\end{tabular}

Fuente: elaboración de la autora.
El modelo matricial No. 2, ilustra una estrategia dominante que favorece el equilibrio de los supuestos cooperativos y no competitivos, de esta forma la Fase I de Indagación y la Fase II de Investigación, obedecen a dos variables colectivas para la efectividad en sus procesos, criterio profesional y transparencia, encontrándose que la estrategia que más beneficia a la cooperatitividad de estas dos fases, es la integración por así decirlo de las dos variables, entendiéndose que son diferentes pero complementarias, así, la entrega (4:4) y (8:8) donde realmente se encuentra el equilibrio surge de T/CP y CP/T, tanto para la fase de indagación como para la fase de investigación, lo que traduce una cooperatitividad permanente, en la planificación y organización que conduzca a objetivas garantías judiciales en la defensa y la acusación, como por ejemplo: la evaluación de los elementos probatorios.

Tabla 3. Modelo Matricial No.2.

${ }^{*}$ Criterio profesional, **Transparencia.

\begin{tabular}{cccc}
\hline \multirow{2}{*}{$\mathrm{Cp}_{*}$} & & \multicolumn{2}{l}{ Investigación } \\
\cline { 2 - 4 } & & \multicolumn{2}{l}{$\mathrm{T}_{* *}$} \\
\hline \multirow{2}{*}{ Indagación } & $\mathrm{Cp}$ & $1: 5$ & $8: 8$ \\
\cline { 2 - 4 } & $\mathrm{T}$ & $4: 4$ & $5: 1$ \\
\hline
\end{tabular}

Fuente: elaboración de la autora.

Este esfuerzo, debe permitir, la realización de una investigación integral, en términos generales, en donde los responsables del proceso, tengan las más altas calificaciones profesionales y de desempeño, e inclusive los más altos antecedentes éticos, para procurar fortalecer la función investigativa de la Fiscalía General de la Nación ${ }^{6}$ y en complementariedad directa el principio de transparencia.

En relación con estas implicaciones desde el argumento "la seguridad y defensa nacional guardan una estrecha relación con los derechos humanos", sin duda, la cooperación internacional aporta un planteamiento considerable en el desarrollo y evolución de los derechos humanos

\footnotetext{
${ }^{6}$ Sobre el asunto la Corte Constitucional de Colombia en sentencia C-186/08, confirma los objetivos del Sistema Penal Acusatorio(i) fortalecer la función investigativa de la Fiscalía General de la Nación (ii) propiciar un juicio público, pleno de garantías, oral, contradictorio, concentrado y con inmediación en la incorporación y práctica probatoria; (iii) instituir una clara distinción entre los funcionarios encargados de investigar, acusar y juzgar; (iv) descongestionar los despachos judiciales mediante un sistema procesal basado en la oralidad, que garantice el derecho a un juicio sin dilaciones injustificadas; (v) modificar el principio de permanencia de la prueba por el de la producción de la misma dentro del juicio oral; (vi) introducir el principio de oportunidad; y (vii) dar función efectiva a la figura del juez de control de garantías.
} 
como producto jurídico de la modernidad, en la relación permanente protección y garantía. En la medida, en que haya una verdadera seguridad jurídica para los nacionales de este país, en el marco de un Estado social de derecho, fundamentado en la protección de los derechos y libertades, quedará demostrada una eficaz e eficiente articulación con los micros procesos de justicia.

En otras palabras, capturar soluciones, no teorías o especulaciones; implementando la aplicación y confirmación de las acciones preventivas y acciones correctivas inmediatas que se presenten en el desarrollo de los procesos. Sobre las bases de las ideas expuestas, es necesario generar mecanismos efectivos, además con criterios de transparencia, objetividad e independencia, capaces de identificar los elementos que impiden esclarecer la responsabilidad internacional del Estado.

En este ámbito e independientemente del tipo de proceso involucrado. Se hace necesaria cierta adaptación en la orientación adecuada de una Estrategia Jurídica Ordenada previa vinculación del sistema de equilibrio de los supuestos cooperativos y no competitivos, que debería establecer interfaces que bloquen la impunidad, como un factor importante a la hora de implementar la solución en la óptica de la legalidad:

- Aportar los elementos de una profunda investigación interna, legales y reglamentarios de los procesos relacionados (penales y disciplinarios) que permita desvirtuar los hechos denunciados;

- Perfeccionar la instrucción del proceso, determinada la responsabilidad penal y/o disciplinaria. En este contexto la Corte Constitucional de la República de Colombia en Sentencia T-647/13 hace relevancia sobre el debido proceso penal.

- Esclarecer las circunstancias y responsabilidades a que haya lugar como identificar, individualizar y judicializar los presuntos autores del hecho internacionalmente ilícito (refiérase al artículo 5 respecto del Comportamiento de una persona o entidad que ejerce atribuciones del poder público en OEA, A/RES/56/83, (2002).

Para finalizar, se debe entender que la justicia es extremadamente cara, ya que demanda una cantidad de recursos considerable para llevar adelante cualquier tipo de reclamación, y está ligada a una cantidad de procedimientos formales en el sentido que todos deben ser cumplidos, inexorablemente lo cual la hacen lenta presentando demoras injustificadas en la investigación interna, respecto de los procesos relacionados y en muchos casos, se ha sen- tido que la justicia suele estar parcializada con presencia de amenazas y coacciones. Es decir, no siempre los tribunales son completamente independientes de los poderes y de la influencia de los otros poderes. Es evidente que estos problemas deben ser reconocidos dentro de la administración de justicia y empezar a ser trabajados por parte del Estado de manera adyacente.

\section{Conclusiones}

El concepto de "responsabilidad internacional" es altamente controvertible. El objeto de este artículo ha sido identificar la base del patrón que incide, en el aumento de los hechos demandantes por violaciones a los estándares que contempla el Derecho Internacional de los Derechos Humanos, como se ha podido observar la responsabilidad internacional queda demostrada en la inoperancia de la justicia interna del Estado colombiano, lo cual refiere la implementación urgente de mecanismos de seguimiento, monitoreo y control; formulados con criterios alternativos, rápidos, confiables y económicos; a partir de la cooperatitividad y no competencia de las variables de formulación: Criterio Profesional y Transparencia, basadas en la adaptación de un sistema de equilibrio que genera una representación estratégica continua y determinada en la búsqueda permanente de una justicia clara y evidente, que debería asegurar la dinámica del proceso judicial en lo que respecta a la investigación, juzgamiento y sanción de los responsables materiales e intelectuales, así como de los eventuales encubridores.

El patrón aborda la observancia y defensa permanente de los derechos humanos, en su eficacia y eficiencia, a través del estudio de las múltiples herramientas jurídico normativas en el orden internacional y regional. Además, sugiere la implementación de medidas legislativas, administrativas, judiciales y de otro carácter, adecuadas y efectivas en el régimen interno, a través de la orientación de una Estructura Jurídica Organizada, que evidencie de manera transparente una verdadera evolución jurídica desde la óptica de la legalidad.

En consecuencia, la dificultad estriba en que si la integración de los derechos humanos en el derecho internacional ha ampliado el ámbito de este último, dicha integración ha politizado al mismo tiempo el problema, y sería equivocado ver en ella únicamente un triunfo de la ética sobre la política; lo inverso es igualmente cierto, pues la protección de los derechos humanos se ha convertido también en política, y ésta, como toda política, es selectiva y discriminatoria. 
CIENCIA Y PODER AÉREO | Revista Científica de la Escuela de Postgrados de la Fuerza Aérea Colombiana | Vol. 10 | Enero - Diciembre de 2015

Las ventajas y las desventajas se reproducen mutuamente. Los que tienen discernimiento, reflexionan.

Ho Yen-hsi

El Arte de la Guerra

\section{Referencias}

Alexy, R. (1993). Teoría de los derechos fundamentales. Madrid: Fareso S.A.

Camargo, P. (2012). Manual de derechos humanos. Bogotá: Leyer.

Camargo, P. (2013).Tratado de derecho internacional Público. Bogotá: Leyer.

Campos, M. (2008). A Dictionary of Human Rights. España: Ariel.

Cid, M. (2008). La Corte Penal Internacional. Madrid: Dykinson, S. L.

Dulitzky, A., Martin, C., Rodríguez, D., Pinzón y Guevara, J. (2006). Alcance de las obligaciones internacionales de los derechos humanos. Derecho Internacional de los Derechos Humanos. : México: Universidad Iberoamericana, A.C.

Fajardo, L. (2010). Implementación del Sistema Interamericano de Derechos Humanos en Colombia a través del bloque de constitucionalidad. Bogotá: Biblioteca Jurídica Diké.

León, C. (2010). La interpretación de los derechos fundamentales según los tratados internacionales sobre los derechos humanos. España: Reus S.A.

Nash, J. (1950). Non-Cooperative Games. Tesis de Doctorado para la obtención del título de Doctor en Philosofía. Facultad de Philosofía, Princeton University de Nueva Jersey, Estados Unidos.

Neira, J. (2008). El buen servidor público. Bogotá: Imprenta Nacional de Colombia.

Nikken, P. (1989).El Derecho Internacional de los Derechos Humanos. Revista de la Facultad de Ciencias Jurídicas y Políticas (1989), pp. 1-37.

O’Donnell, D. (2012).Derecho Internacional de los Derechos Humanos: normativa, jurisprudencia y doctrina de los Sistemas Universal e Interamericano. México: Tribunal Superior de Justicia del Distrito Federal.

Organización de Naciones Unidas, (2013). Recopilación preparada por la Oficina del Alto Comisionado para los Derechos Humanos. Washington: Colombia

Organización de Naciones Unidas. (2006). Informe Naciona1 del Consejo de Derechos Humanos. Washington D.C.: Colombia.

Ortiz, L., Martin, C.; Rodríguez, D.; y Guevara, J. (2006). Fuentes del Derecho Internacional de los Derechos Humanos. México: Universidad Iberoamericana.

Programa Presidencial de Derechos Humanos y DIH. (2010). Proyecto Lucha Contra la Impunidad-PLCl, Fase-II. Bogotá: Ediprime.

Ramelli, A. (2004). Sistemas de fuentes del derecho internacional público y bloque de constitucionalidad en Colombia. Revista Mexicana de Derecho Constitucional (11), p. 160.

Reyes, E. (2007). Celebración y jerarquía de los tratados de derechos humanos Colombia y Venezuela. Caracas: Universidad Católica Andrés Bello.

Rodríguez, G., Martin, C., Rodríguez, D., Pinzón y Guevara, J. (2006). Normas de responsabilidad internacional de los Estados. Derecho Internacional de los Derechos Humanos. México: Universidad Iberoamericana, A.C.

Secretaria General OEA. Texto: Serie sobre Tratados, OEA, No. 36, registro ONU: 08/27/79 No. 17955 Vol. Recuperado de htpp:// www.oas.org/.../tratados_b-32_convencion_americana_sobre_derechos_

Tzu, S. (1982). El Arte de la Guerra. Bogotá: Skla.

Uprimy, R.; Uprimy, I. y Parra, O. (2008). Derechos humanos y derecho internacional humanitario. Escuela Judicial "Rodrigo Lara Bonilla". Bogotá: Imprenta Nacional de Colombia.

Vasco, M. (1986). Diccionario de Derecho Internacional. Universidad de Texas: Casa de la Cultura Ecuatoriana "Benjamín Carrión".

Villacís, B. (2006). La Convención de Viena sobre Derechos de los Tratados. Recuperado de http://www.afese.com/img/revistas/ revista49/convencionviena.pdf

\section{Normas Consultadas}

Comisión Interamericana de Derechos Humanos. (1985). Convención Interamericana para Prevenir y Sancionar la Tortura. [En línea] Disponible en http://www.cidh.oas.org/

Comisión Interamericana de Derechos Humanos. (1994). Convención Interamericana sobre Desaparición forzada de personas. [En línea] Disponible en http://www.cidh.oas.org/

Comisión Interamericana de Derechos Humanos. (1990). Protocolo a la Convención Americana sobre la Abolición de la pena de muerte. [En línea] Disponible en http://www.cidh.oas.org/

Comisión Interamericana de Derechos Humanos. (1999). Convención Americana para la eliminación de todas las formas de discriminación contra las personas con discapacidad. [En línea] Disponible en http://www.cidh.oas.org/

Comisión Interamericana de Derechos Humanos. (1994). Comisión Interamericana de Derechos Humanos Convención para prevenir, sancionar y erradicar la violencia contra la Mujer, Belem do Para. [En línea] Disponible en http://www.cidh.oas.org/

Corte Penal Internacional. (1998). Estatuto de Roma de la Corte Penal Internacional. La Haya: ONU.

Corte Internacional de Justicia. (1978). Reglamento de la Corte Internacional de Justicia. Documentos en español. La Haya: ONU.

Corte Interamericana de Derechos Humanos. (2009). Reglamento de la Corte Interamericana de Derechos Humanos. [En línea] Disponible en: http://www.corteidh.or.cr/

106 | La responsabilidad internacional del Estado colombiano ante la Corte Interamericana de Derechos Humanos por la inoperancia de la justicia interna. 
Organización de los Estados Americanos. (1969). Convención Americana sobre Derechos Humanos. Conferencia Especializada Interamericana sobre Derechos Humanos. Washington D.C.: Departamento de Derecho Internacional.

Organización de los Estados Americanos. (2002). Responsabilidad del Estado por hechos internacionalmente ilícitos. Washington D.C.: Departamento de Derecho Internacional.

Organización de los Estados Americanos. (1969). Convención de Viena sobre el Derecho de los Tratados celebrados entre Estados y Organizaciones Internacionales o entre Organizaciones Viena, Austria. Washington D.C.: Departamento de Derecho Internacional.

Organización de los Estados Americanos. (1966). Protocolo a la Convención Americana sobre derechos económicos, sociales y culturales. Washington D.C.: Departamento de Derecho Internacional.

Organización de las Naciones Unidas. (1945). Carta de la Organización de las Naciones Unidas. Conferencia de las Naciones Unidas sobre Organización Internacional San Francisco. New York: Documentos Importantes.

Organización de las Naciones Unidas. (1948). Declaración Universal de los Derechos Humanos. New York: Departamento de Información Pública.

Organización de las Naciones Unidas. (1966). Pacto Internacional de Derechos Civiles y Políticos. Departamento de Derechos Humanos. Recuperado de http://www.ohchr.org/SP

Senado de la República. (2009). Constitución Política de Colombia. Bicentenario de la Independencia de Colombia 1810 - 2010. Bogotá: Imprenta Nacional de Colombia.

Colombia, Congreso de la República, (14 de enero de 2005), "Ley Sistema Nacional de Defensoría Pública", Ley 941/05.

Colombia, Congreso de la República, (25 de julio de 2005), “Ley de Justicia y Paz", Ley 975/05.

Colombia, Congreso de la República, (31 de agosto de 2004), "Ley Código de Procedimiento Penal", Ley 906/04.

Colombia, Congreso de la República, (14 de enero de 2000), "Ley Código de Procedimiento Penal", Ley 600/00.

\section{Jurisprudencia}

Corte IDH, Opinión Consultiva OC-6/86 del 9 de mayo de 1986. Serie A No. 6.

Caso Rodríguez Vera y otros (Desaparecidos del Palacio de Justicia) Vs. Colombia. Sentencia de 14 de noviembre de 2014. Serie C No. 287

Caso de las Comunidades Afrodescendientes Desplazadas de la Cuenca del Río Cacarica (Operación Génesis) Vs. Colombia. Sentencia de 20 de noviembre de 2013. Serie C No. 270.

Caso Masacre de Santo Domingo Vs. Colombia. Sentencia de 19 de agosto de 2013. Serie C No. 263.Sentencia de 30 de noviembre de 2012. Serie C No. 259.
Caso Vélez Restrepo y Familiares Vs. Colombia. Sentencia de 3 de septiembre de 2012 Serie C No. 248.

Caso Manuel Cepeda Vargas Vs. Colombia. Sentencia de 26 de mayo de 2010. Serie C No. 213.

Caso Valle Jaramillo y otros Vs. Colombia. Sentencia de 7 de julio de 2009 Serie C No. 201.Sentencia de 27 de noviembre de 2008. Serie C No. 192.

Caso Escué Zapata. Vs. Colombia. Sentencia de 5 de mayo de 2008 Serie C No. 178.Sentencia de 4 de julio de 2007. Serie C No. 165.

Caso de la masacre de La Rochela Vs. Colombia. Sentencia de 28 de enero de 2008 Serie C No. 175.Sentencia de 11 de mayo de 2007. Serie C No. 163.

Caso de la Masacre de Pueblo Bello Vs. Colombia. Sentencia de 25 de noviembre de 2006. Serie C No. 159.Sentencia de 31 de enero de 2006. Serie C No. 140.

Caso de las Masacres de Ituango Vs. Colombia. Sentencia de 1 de julio de 2006 Serie C No. 148

Caso de la "Masacre de Mapiripán" Vs. Colombia. Sentencia de 15 de septiembre de 2005. Serie C No. 134.Sentencia 7 de marzo 2005. Serie C No. 122.

Caso Gutiérrez Soler Vs. Colombia. Sentencia de 12 de septiembre de 2005. Serie C No. 132.

Caso 19 Comerciantes Vs. Colombia. Fondo, Reparaciones y Costas. Sentencia de 5 de julio de 2004. Serie C No. 109.Sentencia de 12 de junio de 2002. Serie C No. 93.

Caso Las Palmeras Vs. Colombia. Reparaciones y Costas. Sentencia de 26 Noviembre de 2002. Serie C No. 96.Sentencia de 4 de febrero de 2000. Serie C No. 67.

Caso Velásquez Rodríguez Vs. Honduras. Sentencia de 29 de julio de 1998.

Caso Caballero Delgado y Santana Vs. Colombia. Reparaciones y Costas. Sentencia de 29 de enero de 1997. Serie C No. 31.Sentencia de 8 de diciembre de 1995. Serie C No. 22.Sentencia de 21 de enero de 1994. Serie C No. 17.

Los textos íntegros de las Sentencias puede consultarse en el siguiente enlace: http://www.corteconstitucional.gov.co/relatoria/

Corte Constitucional de la República de Colombia, Bogotá.

CConst, C-186/2008, J. Araujo. \& M. Cepeda.

CConst, C-760/2001, J. Araujo. \& M. Cepeda \& Otros.

CConst, C-251/1997, J. Arango. \& E. Cifuentes.

CConst, C-029/1995, J. Arango. \& E. Cifuentes \& Otros.

Diario oficial, Núm.36856 del 13 de febrero de 1985. Bogotá. 
